\title{
A HYBRID APPROACH FOR IPFC LOCATION AND PARAMETERS OPTIMIZATION FOR CONGESTION RELIEF IN COMPETITIVE ELECTRICITY MARKET ENVIRONMENT
}

\author{
Konduru VM ManoharVarma ${ }^{1}, \operatorname{Varaprasad}^{2}$ \\ ${ }^{1}$ Student, Electrical and Electronics Engineering, Christ University, Karnataka, India \\ ${ }^{2}$ Faculty, Electrical and Electronics Engineering, Christ University, Karnataka, India
}

\begin{abstract}
The deregulated power system operation with competitive electricity market environment has been created many challenging tasks to the system operator. The competition with strategic bidding has been resulted for randomness in generation schedule, load withdrawal and power flows across the network. The economic efficiency of electricity market is mainly dependent on network support. In the event of congestion, it is required to alter the base case market settlement and hence the economic inefficiency in terms of congestion cost can occur. In order to anticipate congestion and its consequences in operation, this paper has been considered Interline Power Flow Controller (IPFC).This article proposed a tactical approach for optimal location and then its parameters in Decoupled Power Injection Modeling (DPIM) are optimized using Gravitational Search Algorithm (GSA). The case studies are performed on IEEE 30-bus test system and the results obtained are validating the proposed approach for practical implementations.
\end{abstract}

Keywords: Deregulated power system, competitive electricity market, congestion management, IPFC, Gravitational Search Algorithm (GSA)

\section{INTRODUCTION}

Due to the insecurity operations in interconnected systems so many blackouts have been occurred in recent times. In deregulated power system operational security plays a vital role and execution is tough task due to variations in loads and instability environment. Any changes in the system operations will impact on the market economics due to the power system network and markets are strongly coupled. Based on the qualitative understanding on interactions of both power system security and market operations, the quantification of impacts on market economics due to operational security is not performed. This article proposed an approach to quantify the impacts of market economics based on operational security in the presence of strategic bidding and load variations. We illustrate the application of strategic bidding to the IEEE-30 bus system for the study of its impacts of variation in load periodically in a day-ahead energy market.

We also planned to mitigate congestion by the integration of Flexible AC Transmission Systems (FACTS) devices in the network. The congestion can be alleviated through system reconfiguration and re-dispatch of the system load. This has not much before or after the deregulation and is proved a security constrained economic dispatch. Financial settlement is a major difference of before and after deregulation. In the present competitive market congestion is a major concern due to it will block the competition between the markets. The present trend in congestion management is to use pricing tools in the form of nodal and zonal pricing. Despite these tools, the congestion is still in the place and it is increasing alarmingly. Congestion management includes both the congestion relief actions and the associated pricing mechanisms [1]. Congestion relief by re-dispatch will causes to increase generation cost and hence by means of reconfiguration, erection of new transmission lines or integration of FACTS device can adopt. But due to Right of Way (RoW) and cost concerns, instead of erection of new transmission lines FACTS devices can be the better option. Since congestion is uneconomical and undesirable in market operation as well as system security, the validation of FACTS devices should address technical as well as economical benefits. Among all the FACTS devices Interline Power Flow Controller (IPFC) is a versatile device to control power flow in many transmission lines simultaneously. Several references in technical literature can be found on application of IPFC for congestion management. In [2], the IPFC is applied for congestion relief, power flow control and to minimize the transmission losses. In [3], the congestion relief has been achieved by the application of IPFC and GUPFC in strategic bidding environment. The impact of these FACTS devices as shown economically via reduction in transmission congestion cost. In [4], the voltage security improvement and congestion alleviation have done by placing Static Synchronous Compensator (STATCOM) and IPFC using artificial intelligence. In [5], both real and reactive power flow has been equalized by using IPFC and Unified Power Flow Controller (UPFC). In [6], optimizing production cost and congestion alleviation has done by locating IPFC in 
deregulated power system using PSO algorithm. In this article the parameters have been optimized using Gravitational Search Algorithm (GSA). In [7], new optimization algorithm is introduced, which is based on law of gravity and mass interaction and also compared new algorithm with other popular algorithms. In [8], gives detailed review on GSA and future possibilities and applications with GSA. The GSA has been used in so many applications of power system [9][10][11][12].

This paper is outlined as follows: After introduction, section 2 describes the market settlement mechanism in competitive electricity market. In section 3, the power injection modeling (PIM) of IPFC, strategy for its location are explained. In section 4, the heuristic optimization technique GSA application for optimization of IPFC parameters is explained. In section 5, the case studies and discussions are illustrated with IEEE-30 bus system network. After section 5 , the comprehensive conclusions are given.

\section{COMPETITIVE ELECTRICITY MARKET}

The strategic bidding is a process of change in bid functions to maximize GENCOs' profit. In a perfect competitive market, the supply curve is drawn by consolidating generator offers should closely approximate the system marginal production cost of generation [13]. Hence the bidding cost function treated as a continuous function and is given by a power producer $i$ (or supply curve) is:

$$
C_{b i}\left(P_{g i}\right)=a_{b i} P_{g i}^{2}+b_{b i} P_{g i}+c_{b i}
$$

Where $\left(a_{b i}, b_{b i}\right.$ and $\left.c_{b i}\right)$ are the bid coefficients and related with the actual cost function coefficients $\left(a_{i}, b_{i}\right.$ and $\left.c_{i}\right)$ as follows:

$$
\xi_{i}=\frac{a_{b i}}{a_{i}}=\frac{b_{b i}}{b_{i}} \text { and } c_{b i}=c_{i}
$$

Where $\xi_{i}$ is the bidding parameter and represents mark-up above or below the marginal cost that a generator $i$ decide to set its marginal bid in competitive market. Now, the marginal cost function will become as:

$$
C_{b i}\left(P_{g i}\right)=\xi_{i} a_{i} P_{g i}^{2}+\xi_{i} b_{i} P_{g i}+c_{i}
$$

Then the equations for $P_{g i}$ and $\lambda_{M C P}$ will change as follows and the rest of procedure is as economic dispatch problem.

$$
\lambda_{M C P}=\frac{P_{D}+\sum_{i \in N G} \frac{b_{i}}{2 \xi_{i} a_{i}}}{\sum_{i \in N G} \frac{1}{2 \xi_{i} a_{i}}}
$$

$$
P_{g i}=\frac{\lambda_{M C P}-\xi_{i} b_{i}}{2 \xi_{i} a_{i}}
$$

Now considered the effect of generator limits given by the inequality constraint:

$$
0 \leq P_{g i} \leq P_{g i}^{\max } \quad \forall i \in N G
$$

If a particular generator loading $P_{g i}$ reaches the maximum limit $P_{g i}^{\max }$, its loading is fixed and remaining demand will be shared by other generators participating in the network on an equal incremental cost.

\section{INTERLINE POWER FLOW CONTROLLER}

The Interline Power Flow Controller (IPFC) main objective is to offer a complete power flow control scheme for a power transmission system, in which multiple lines are employed with a Static Synchronous Series Compensator (SSSC) for series compensation as shown in Fig. 1. The IPFC scheme has the tendency to transfer real power and separate control of reactive power in each line. The IPFC will be made both real power and reactive power equal between the lines, so that the power transfer capability will be increased and the lines which are over loaded come down to under loaded. The IPFC will decrease the stability problems in power system network [14].

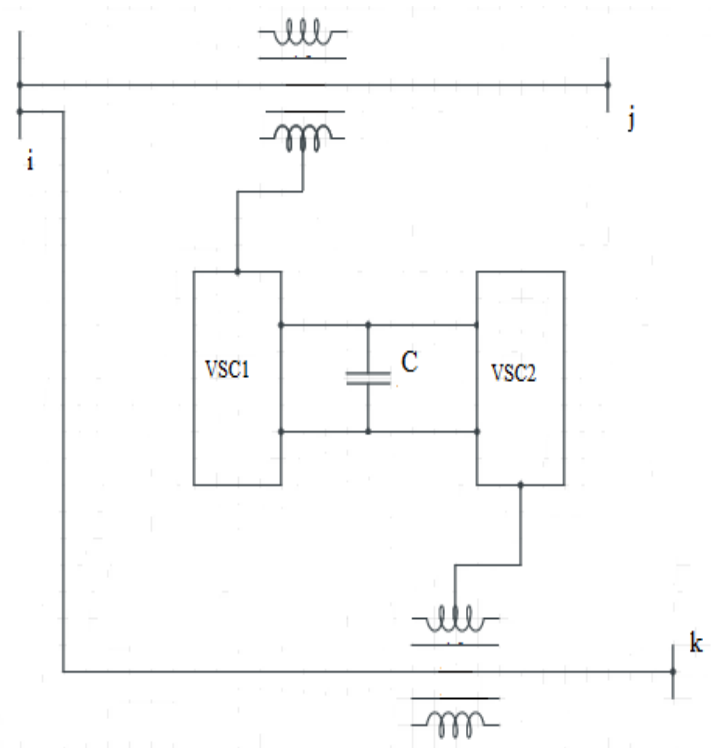

Fig.1 Schematic representation of IPFC

Fig.2 represents the equivalent circuit of the IPFC. This arrangement has two voltage sources V1pq and V2pq in series with transmission Lines 1 and 2, represent the two back to back converters. The common dc link is represented by a bidirectional link $(\mathrm{P} 12=\mathrm{P} 1 \mathrm{pq}=\mathrm{P} 2 \mathrm{pq})$ for real power exchange between the two voltage sources. $V_{1 S}$ and $V_{1 R}$ are the sending and receiving end voltages of transmission line1 and $X_{1}$ is the line- 1 reactance. $V_{2 S}$ and $V_{2 R}$ are sending and 
receiving end voltages of transmission line- 2 and $X_{2}$ is the line- 2 reactance.

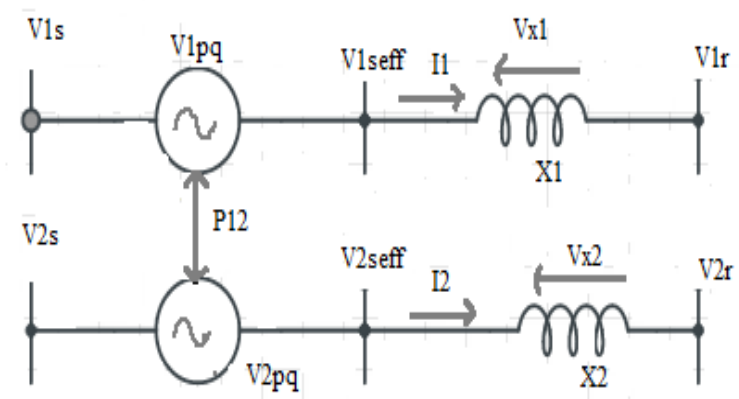

Fig.2 equivalent circuit of IPFC

\subsection{Injection Model of IPFC}

Fig. 3 shows the equivalent circuit of two converter IPFC. Vi , $\mathrm{Vj}$ and $\mathrm{Vk}$ are the complex bus voltages at the buses $\mathrm{i}, \mathrm{j}$ and $\mathrm{k}$ respectively.

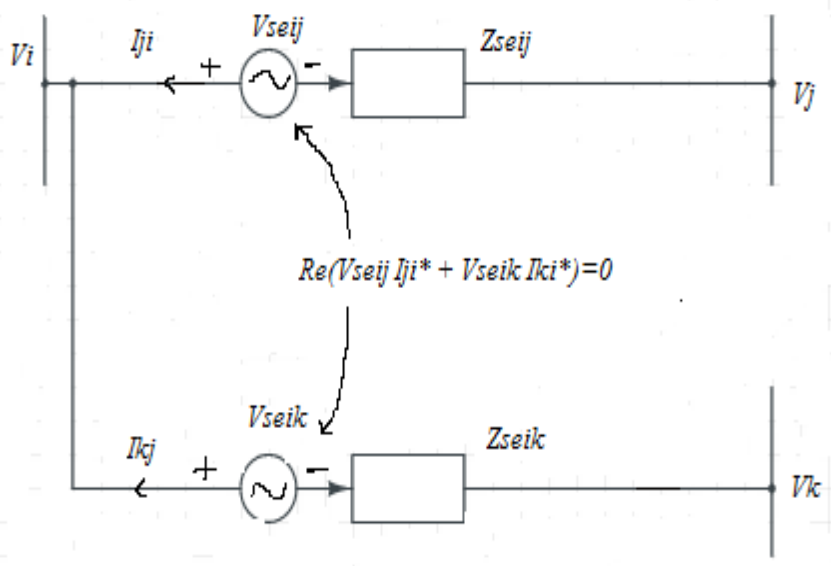

Fig.3 Equivalent circuit of two converter IPFC

The current source from the equivalent circuit is represented as follows

$$
\mathrm{I}_{s e_{i n}}=-j b_{s e_{i n}} V_{s e_{i n}}
$$

Now, the current source can be modeled as injection powers at the buses $i, j$ and $k$. the complex power injected at $i^{\text {th }}$ bus is

$$
\begin{aligned}
S_{i n j, i} & =\sum_{n=j, k} V_{i}\left(-I_{s e_{i n}}\right)^{*} \\
S_{i n j, i} & =\sum_{n=j, k} V_{i}\left(j b_{s e_{i n}} V_{s e_{i n}}\right)^{*}
\end{aligned}
$$

After simplification, the active power and reactive power injections at $i^{\text {th }}$ bus are

$$
\begin{aligned}
& P_{i n j, i}=\operatorname{Re}\left(S_{i n j, i}\right)=\sum_{n=j, k}\left(V_{i} b_{s e_{i n}} V_{s e_{i n}} \sin \left(\theta_{i}-\theta_{s e_{i n}}\right)\right) \\
& Q_{i n j, i}=\operatorname{Im}\left(S_{i n j, i}\right)=\sum_{n=j, k}\left(V_{i} b_{s e_{i n}} V_{s e_{i n}} \cos \left(\theta_{i}-\theta_{s e_{i n}}\right)\right)
\end{aligned}
$$

The complex power injected at $n^{\text {th }}$ bus $(\mathrm{n}=j, k)$ is

$$
\begin{aligned}
& S_{i n j, \mathrm{n}}=\sum_{n=j, k} V_{n}\left(-I_{s e_{i n}}\right)^{*} \\
& S_{i n j, \mathrm{n}}=\sum_{n=j, k} V_{n}\left(j b_{s e_{i n}} V_{s e_{i n}}\right)^{*}
\end{aligned}
$$

After simplification, the active power and reactive power injections at $n^{\text {th }}$ bus are

$$
\begin{aligned}
& P_{i n j, \mathrm{n}}=\operatorname{Re}\left(S_{i n j, \mathrm{n}}\right)=\sum_{n=j, k}\left(V_{n} b_{s e_{i n}} V_{s e_{i n}} \sin \left(\theta_{n}-\theta_{s e_{i n}}\right)\right) \\
& Q_{i n j, \mathrm{n}}=\operatorname{Im}\left(S_{i n j, \mathrm{n}}\right)=\sum_{n=j, k}\left(V_{n} b_{s e_{i n}} V_{s e_{i n}} \cos \left(\theta_{n}-\theta_{s e_{i n}}\right)\right)
\end{aligned}
$$

The placement of IPFC plays a vital role for congestion management. Placement of IPFC can be done with different optimization techniques, among all optimization techniques Particle Swarm Optimization gives precise and quick results. So, in this paper optimal location of IPFC is done by using PSO. After placement, parameters of IPFC are very important, optimal parameters can be chosen based on the location. In this paper for optimal parameters are done by using GSA.

\section{PROPOSED HYBRID APPROACH}

The placement of IPFC plays a vital role for congestion management. Placement of IPFC can be done with different optimization techniques, among all optimization techniques Particle Swarm Optimization (PSO) gives precise and quick results. So, in this paper optimal location of IPFC is done by using PSO with an objective of voltage profile improvement. After placement, the IPFC parameters are optimized by using GSA technique.

\subsection{PSO for Voltage Improvement}

According to computer science technology, particle swarm optimization (PSO) is a computational method that gives optimized solution for a given problem in iterative way for required output [22]. PSO having the dubbed particles, which are having the required solutions and these particles are searched in the search space according to the mathematical formulae over the particle position and velocity.

General algorithm is proposed by Kennedy and Eberhart $x_{i}^{k}$ - Particle position

$v_{i}^{k}$ - Particle velocity

$p_{i}^{k}$ - Best individual particle position

$p_{k}^{g}$ - Global best particle position 
$C_{1}, C_{2}-$ cognitive and social parameters

$r_{1,} r_{2} \quad-$ arbitrary numbers between 0 and 1

Position of individual particles represented as follows

$$
x_{i}^{k+1}=x_{i}^{k}+v_{i}^{k+1}
$$

With the velocity calculated using below mathematical formulae

$$
v_{i}^{k+1}=v_{i}^{k}+c_{1} r_{1}\left(p_{i}^{k}-x_{i}^{k}\right)+c_{2} r_{2}\left(p_{k}^{g}-x_{i}^{k}\right)
$$

\section{Algorithm of particle swarm optimization}

Step by step algorithms as follows:

1. Initialize

a. Set constants $k_{\max }, c_{1}, c_{2}$.

b. Arbitrarily initialize particle positions $x_{0}^{i} \in \mathrm{D}$ in $I R^{n}$ for $i=1, \ldots \ldots, p$.

c. Arbitrarily initialize particle velocities $0 \leq v_{0}^{i} \leq$ $v 0 \max \in \mathrm{D}$ in IRnfor $i=1, \ldots . ., p$.

d. Set $k=1$.

2. Optimize
a. Evaluate $f_{k}^{i}$ using design space coordinates $x_{k}^{i}$.
b. If $f_{k}^{i} \leq f_{\text {best }}^{i}$ then $f_{\text {best }}^{i}=f_{k}^{i}, p_{k}^{i}=x_{k}^{i}$
c. If $f_{k}^{i} \leq f_{\text {best }}^{g}$ then $f_{\text {best }}^{g}=f_{k}^{i}, p_{k}^{g}=x_{k}^{i}$
d. If stopping condition is satisfied then go to step 3 .
e. Update particle velocities $v_{k}^{i}$ for $i=1, \ldots \ldots, p$.
$f$. Update particle positions $\quad x_{k}^{i}$ for $i=1, \ldots \ldots, p$.
g. Increment $k$.
h. go to 2(a).

3. Stop

\subsection{GSA for Optimizing Parameters of IPFC}

In GSA algorithm all agents are contemplated as objects. All the objects are attracting each other based on the gravitational force of particular object. The low mass objects will move towards the heavier mass objects. The heavier mass objects which are having candidate solution will move very slow compare to the other objects [20].

In GSA, each agent has four specifications: position, inertial mass, active gravitational mass, and passive gravitational mass. The position of the agent correlate with panacea of the problem, and its gravitational and inertial masses are determined by using a fitness function.

The GSA could be treated as a separate system of masses. It is like a small synthetic world of masses obeying the Newton laws of gravitation and motion.

Algorithm of gravitational search algorithms as follows Step1. Identification of search space.

Step2. Initial popular generation between maximum and minimum .

Step3. Fitness evaluation of objects.

Step4. Update $G(t)$, best $(t)$, worst $(t)$ and $M i(t)$ for $i=1 \ldots m$

Step5. Total force calculation in different directions.

Step6. Velocity and acceleration calculations.
Step7. Updating objects' position.

Step8. Repeat step 3 to step 7 until the stop criteria is reached.

Step9. Stop.

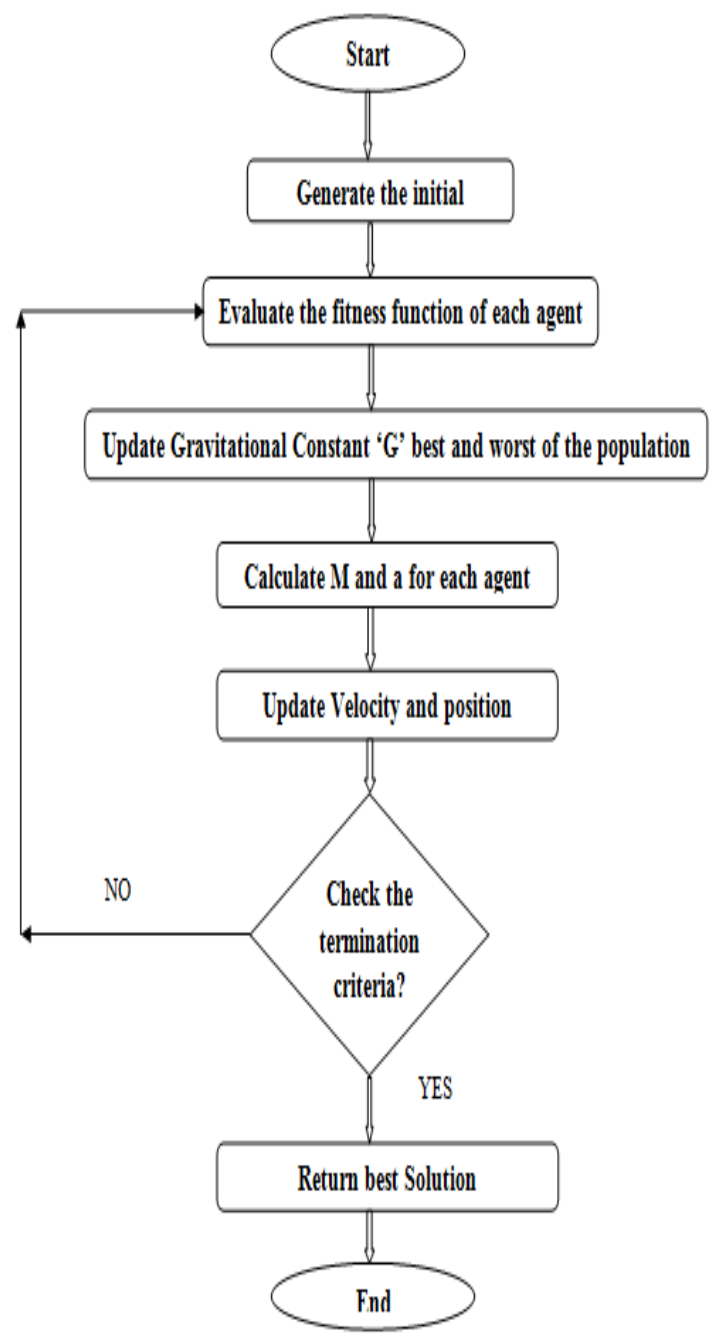

Fig.4 Gravitational search algorithm flow chart

\section{CASE STUDIES}

The proposed is approached is applied for IEEE-30 bus system. The cost coefficients are manipulated according to according to strategic bidding parameter. The total system has been divided into two areas in which area1 has generator buses 1 and 2, area2 has generator buses 13, 22, 23 and 27. With normal bidding parameter and for base case load, the generation schedule has been determined as explained in section II. In area 1, The market is cleared at 3.5233 \$/MWh and the total cost is $243.2242 \$$. Similarly, in area 2 the market is cleared at $3.9605 \$ / \mathrm{MWh}$ and the total cost is 396.4005 \$. In order to optimize economics in both areas simultaneously, the system is considered as one grid consisting of two areas. Under this consideration, the total load is $193.451 \mathrm{MW}$. For this load the market schedule is cleared at 3.8155 \$/MWh and total cost is 630.3476 \$. The market schedules for area1 and area 2 when they are not interconnected are given in Table I and Table II 
respectively. When they are interconnected, the schedule is given in Table III. By observing market schedules in both cases, there is a economic benefit with MW interchange between two areas. Since areal has producing more generation than its own load of $88.751 \mathrm{MW}$, area 2 importing power from area 1 about $17.5935 \mathrm{MW}$. If the network supports for this economic interchange, system operator can reduce a total operating cost of $9.277 \$$. With this schedule the load flow is performed and we have observed the line 10 is overloaded. If a network subject to congestion, the IPFC has to control the power flow in such a way that all transmission lines are below their specified power ratings and so congestion impact on economic interchange can avoid. By placing IPFC in the lines connected between buses 10,16 and 22. The congestion has been relieved and so market economic inefficiency situation is avoided. In addition to this the voltage profile has been improved and it can observe in Fig.5 and also the losses have been reduced from 9.7146 MW to $7.7402 \mathrm{MW}$.
Table-2: Area 2 generation and cost details

\begin{tabular}{|c|c|c|c|c|c|c|}
\hline $\begin{array}{l}\text { Load } \\
(\mathrm{MW})\end{array}$ & $\begin{array}{l}\text { PG1 } \\
\text { (MW } \\
\text { ) }\end{array}$ & $\begin{array}{l}\text { PG2 } \\
\text { (MW } \\
\text { ) }\end{array}$ & $\begin{array}{l}\text { PG3 } \\
\text { (MW } \\
\text { ) }\end{array}$ & $\begin{array}{l}\text { PG4 } \\
\text { (MW } \\
\text { ) }\end{array}$ & $\begin{array}{l}\text { MCP } \\
(\$ / M W \\
\text { h) }\end{array}$ & $\begin{array}{l}\text { Tot } \\
\text { al } \\
\text { Cos } \\
\text { t (\$) }\end{array}$ \\
\hline 104.7 & 22.58 & 23.68 & 19.21 & 42.59 & 3.96 & $\begin{array}{l}396 . \\
4\end{array}$ \\
\hline
\end{tabular}

Table-3: Interconnected system details

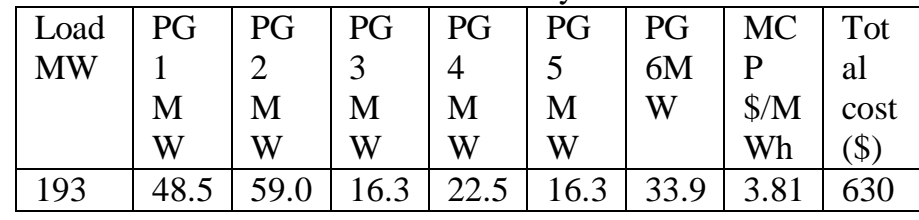

Table-1: Area 1 generation and cost details

\begin{tabular}{|l|l|l|l|l|}
\hline $\begin{array}{l}\text { Load } \\
(\mathrm{MW})\end{array}$ & PG1 (MW) & $\begin{array}{l}\text { PG2 } \\
(\mathrm{MW})\end{array}$ & $\begin{array}{l}\text { MCP } \\
(\$ / \mathrm{MWh})\end{array}$ & $\begin{array}{l}\text { Total } \\
\text { Cost }(\$)\end{array}$ \\
\hline 88.751 & 38.3395 & 50.6672 & 3.5233 & 243.2242 \\
\hline
\end{tabular}

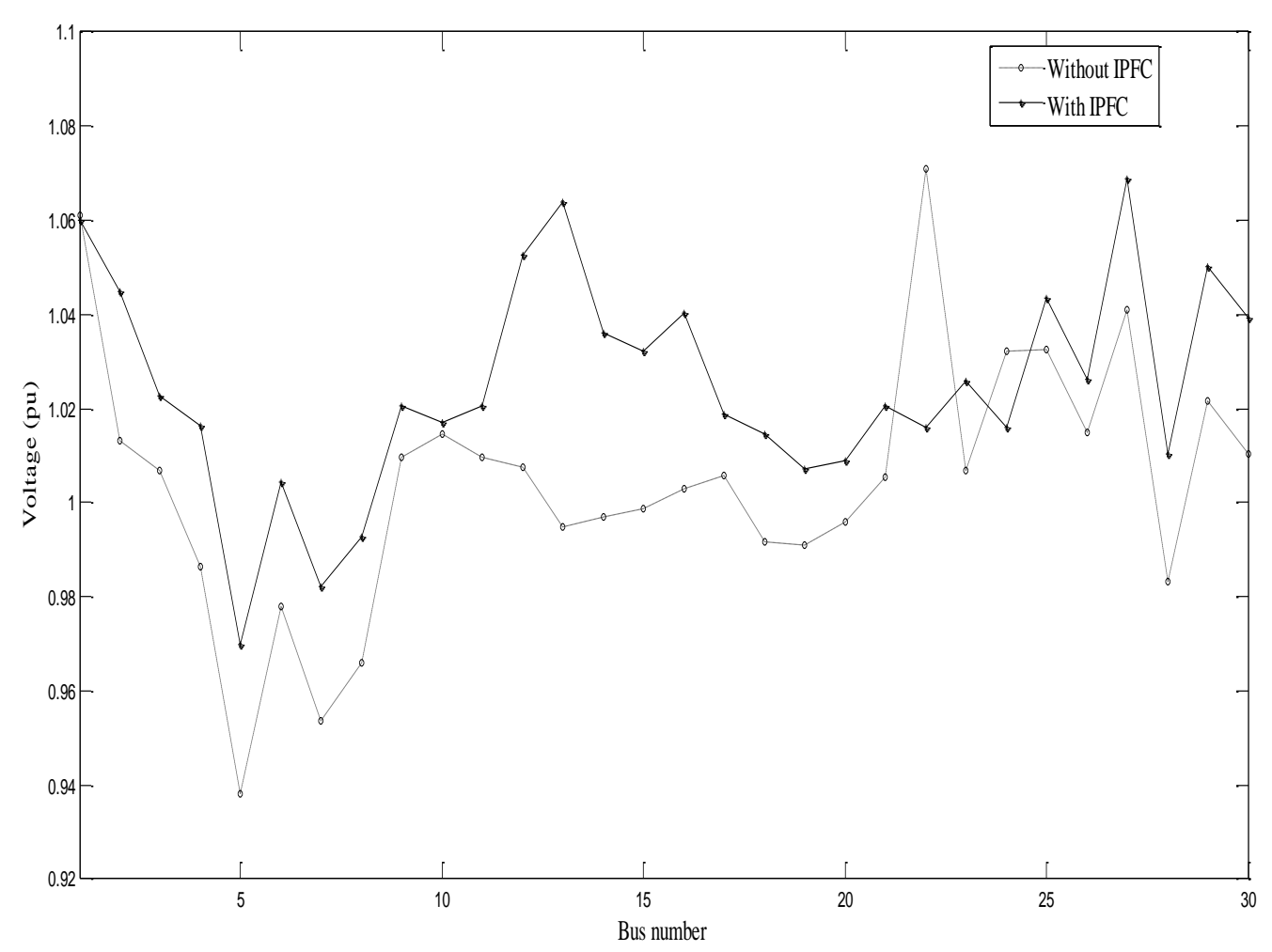

Fig. 5 Changes in voltage profile at base case

The similar procedure is carried out for various loading level at various trading hours with different bidding parameters in different areas. The changes in load for 24 hours span in the form of a load curve are given in Fig.6. 


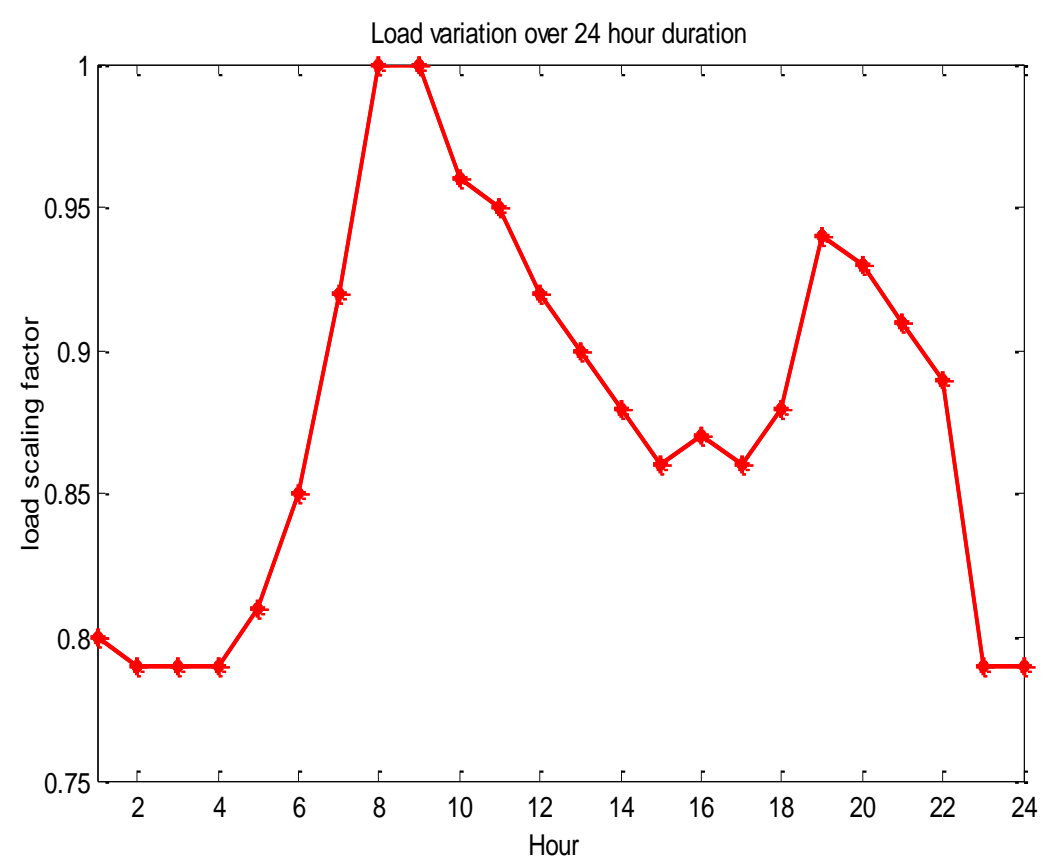

Fig.6 Load curve over 24 hours

The economic and power interchanges for different bidding parameters are shown in Fig.7 and Fig.8. Fig.7 shows when bidding parameters $($ Area1, Area2 $)=(0.5,0.5)=(1,1)=(2,2)$. Fig. 8 shows when bidding parameters $($ Area1, Area2 $)=(1,0.5)=(2,1)$.

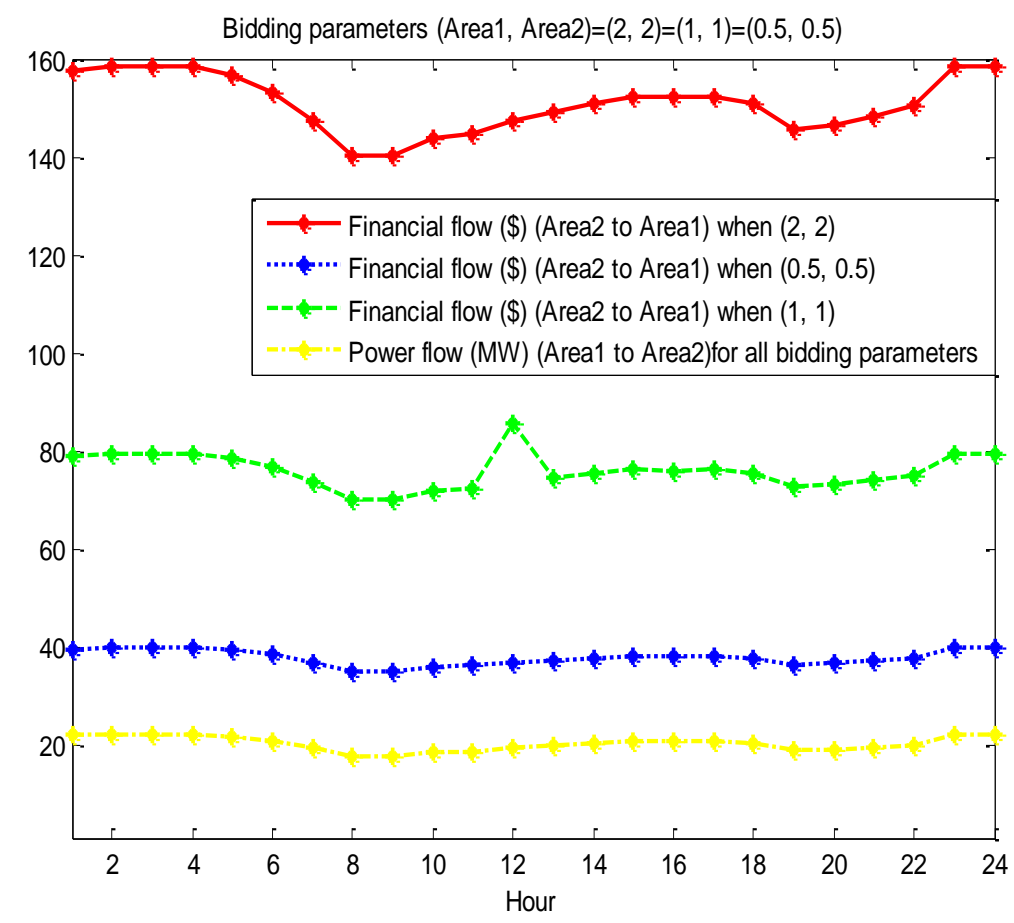

Fig.7 Financial and Power Interchanges 


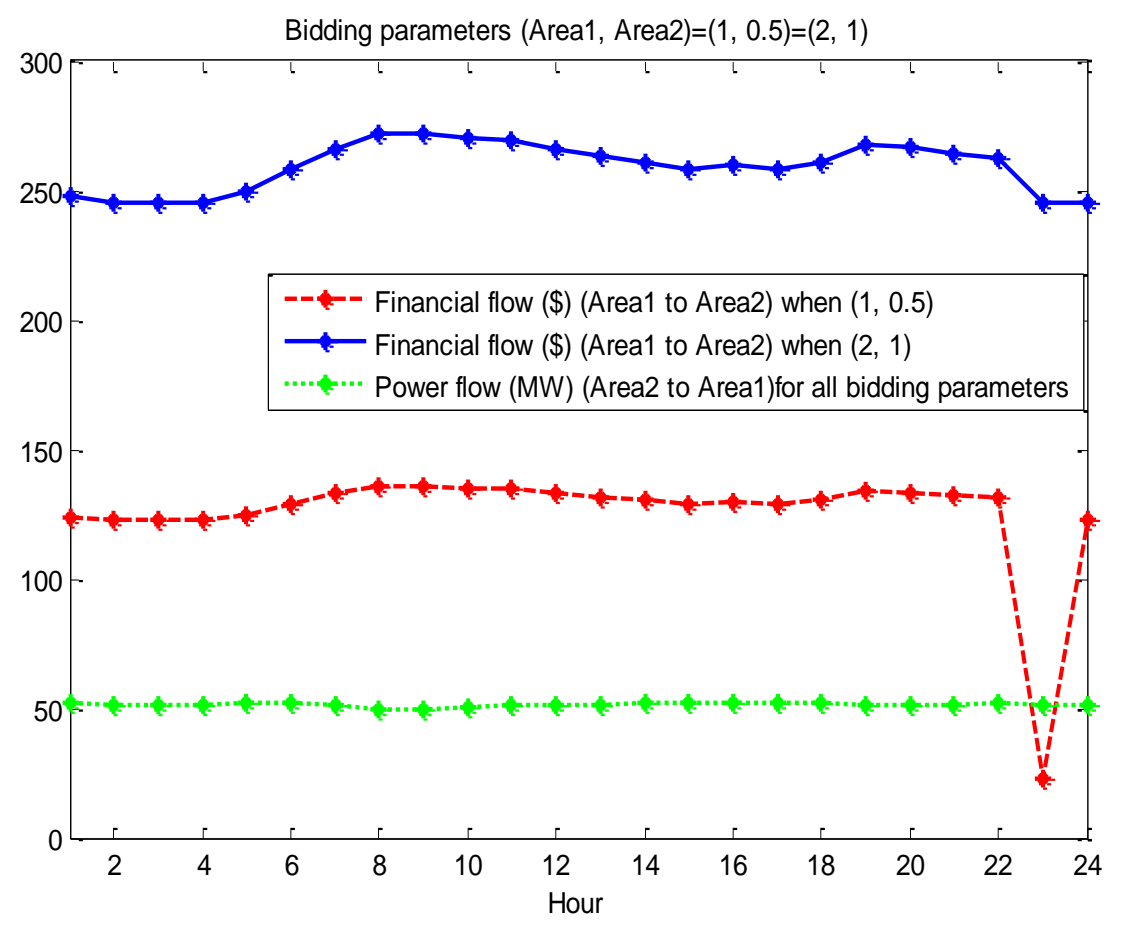

Fig.8 Financial and Power Interchanges

The congestion alleviation is occurred after connected the IPFC. These results are shown in Fig.9 and Fig.10.

Fig.9 shows the congestion alleviation when bidding parameters (Area1, Area2) $=(0.5,0.5)=(1,1)=(2,2)$. During this strategic bidding congestion is occurred in $10^{\text {th }}$ line, when the load at 8,9 and $10^{\text {th }}$ hours. This congestion is mitigated by installing IPFC.

Fig.10 shows the congestion alleviation when bidding parameters (Area1, Area2) $=(1,0.5)=(2,1)$. During this strategic bidding congestion is occurred in $30^{\text {th }}$ line, except the load at $5^{\text {th }}$ hour. This congestion is mitigated by installing IPFC.

In both Fig.9 and Fig.10 the difference of loading on the lines without and with IPFC are shown.

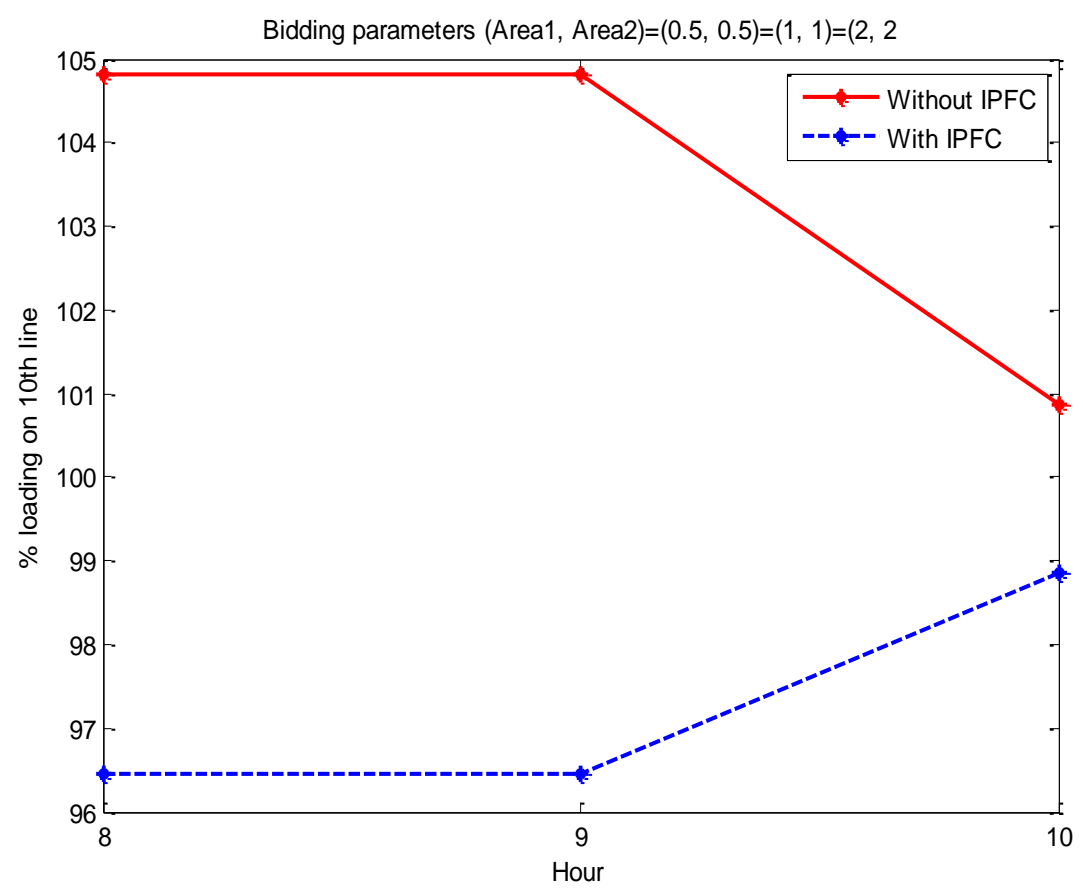

Fig.9 congestion relief in line 10 with IPFC 


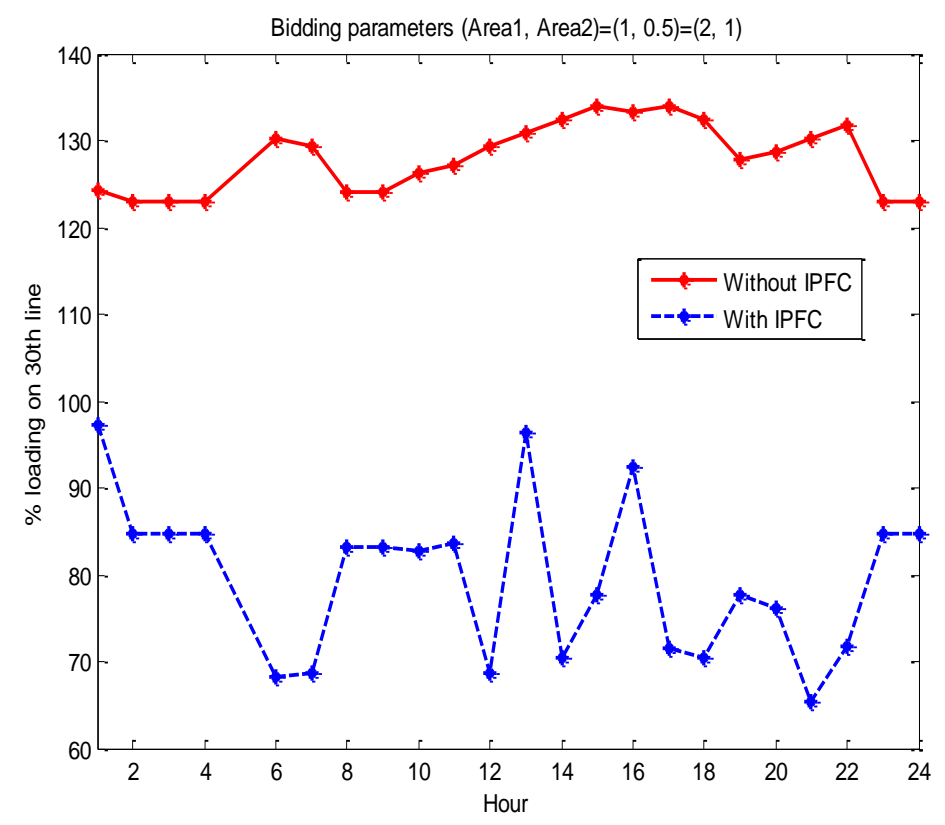

Fig.10 congestion relief in line 30 with IPFC

\section{CONCLUSION}

This paper reviews the competition with strategic bidding in interconnected systems. In addition to this, the stress due to strategic bidding is increased; it leads to congestion in the system. This congestion is alleviated by installing IPFC in proposed IEEE 30-bus system. The case studies are performed on IEEE 30-bus test system and the results obtained are validated the proposed approach for practical implementation. This paper includes only generation side bidding, it will be useful for further study on both generation side and distribution side biddings.

\section{REFERENCES}

[1]. Lommerdal, M. Soder, L., "simulation of congestion management Methods", IEEE Power Tech, Bologna, Volume 2, 23-26 June 2003.

[2]. Zhang, J., "Optimal Power Flow Control for Congestion Management by Interline Power Flow Controller (IPFC)," Power System Technology, 2006. PowerCon 2006. International Conference on , vol.,no., pp.1,6, 22-26 Oct. 2006.

[3]. Kumar, Ashwani, "Comparison of IPFC and GUPFC for Congestion management in deregulated electricity markets," Industrial and Information Systems (ICIIS), 2014 9th International Conference on , vol., no., pp.1,7, 15-17 Dec. 2014.

[4]. A.Karami, M.Rashidinejad and A.A.Gharaveisi, "Voltage security enhancement and congestion management via STATCOM \& IPFC artificial intelligence", Iranian Journal of Science \& Technology, Transaction B, Engineering, Vol.31, No.B3, PP 289-301.

[5]. A.Murugan, S.Thamizmani, "Anew approach for voltage control of IPFC and UPFC for power flow management", IEEE Transc, PP. 1376-1381.
[6]. Masoud Mohammad Rahimi Fard, Aref Jalili Irani, “ Location of IPFC for congestion management lines in electricity market restructured using PSO algorithm", Australian Journal of Basic and Applied Sciences, pp.31883196, 2011.

[7]. Esmat Rashedi, Hossein Nezamabadi-por, Saeid Saryazdi, "GSA: A Gravitational Search Algorithm", Elsevier, Information Sciences, pp.2232-2248, 2009.

[8]. Norlina Mohd Sabri, Mazidah Puteh, and Mohamad Rusop Mahmood, "A Review of Gravitational Search Algorithm", Int. J. Advance, Soft Comput, Appl., Vol.5, 2013.

[9]. R. Suresh, C. Kumar, S.Sakthivel and S. Jaisiva, "Applicationa of gravitational search algorithm for real power loss and voltage deviation optimization", IJESIT, Vol $2,2013$.

[10]. N. V. Subba Rao, G. Kesava Rao, S. Sivanagaraju, "Transmission loss allocation with optimal power flow using gravitational search algorithm", IJIRE, Vol 2, 2014.

[11]. Mani Ashouri, Seyed Mehdi Hosseini, “ Application of new hybrid particle swarm optimization and gravitational search algorithm for non convex economic load dispatch problem", Journal of Advances in computer research, Vol.4, pp.41-51, 2013.

[12]. Serhat Duman, Ugur Guvenc, Yusuf Sonmez, Nuran Yorukeren, "Optimal power flow using gravitational search algorithm", Elsevier, Energy conservation and management, pp.86-95, 2012.

[13]. J. Vara Prasad, K Chandra Sekhar, " Evaluation of available transfer capability in a competitive energy market", IEEE Transc.

[14]. Narain G. Hingorani, Laszlo Gyugyi, "Understanding FACTS: Concepts and Technology of Flexible AC Transmission Systems", IEEE press, New-York, 2000. 
[15]. S.C.Srivastava, R.K.Verma, "Impact of FACTS devices on Transmission pricing in a de-regulated electricitymarket", IEEE Trans. 2000,pp. 642-648.

[16]. Gyugyi, L.Sen, K.K. and Schauder, C.D, “ The interline power flow controller concept a new approach to power flow management in transmission systems", IEEE Trans. Power Del..14(3), pp. 1115-1123.

[17]. A. Karami, M. Rashidinejad and A.A. Gharaveisi, "Voltage security enhancement and congestion management via STATCOM \& IPFC using artificial intelligence", Iranian Journal of Science \& technology, Trans.B,Engineering, Vol.31, No.B3, PP 289-301.

[18]. Kennedy Mwanza, You Shi, "Congestion Management: Re-dispatch And application of FACTS", Chalimers university of technology, Goteborg, Sweden, 2006.

[19]. Charles A. Gibson, Harold Zuniga, “ Interchange evaluation for electric power utilities", IEEE Transc., session. 11D3, pp. 820-825.1989.

[20]. I.Sai ram, J. Amarnath, "Optimal setting of IPFC for voltage stability improvement using (GA-GSA) hybrid algorithm", IEEE Conference, 2013.

[21]. William W. Hogan, "Independent system operator (ISO) for a competitive electricity market", Harvard University, June 1998.

[22]. James Kennedy, Russell Eberhart, "Particle Swarm Optimization”, IEEE Transc., pp. 1942-1948, 1995.

[23]. A.R. Abhyankar, prof.S.A.Khaparde, "Introduction to deregulation in power industry", IIT Bombay.

\section{BIOGRAPHIES}

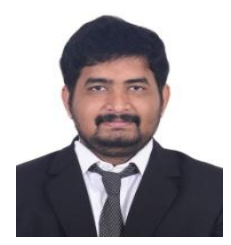

Konduru VM ManoharVarma is an M.Tech candidate in the department of Electrical \& Electronics Engineering at the Christ University, Bengaluru. He has done B.Tech in Electrical \& Electronics Engineering from Jawaharlal Nehru Technological University, Anantapur. His areas of interests are power systems stability and FACTS.

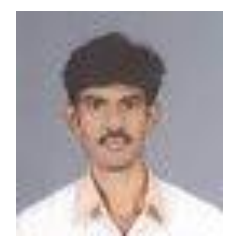

J.VaraPrasad is a Ph.D. Candidate in the department of Electrical \& Electronics Engineering at the University of Acharya Nagarjuna at Guntur (India). $\mathrm{He}$ has received his $M$. Tech in Power System Engineering from the University of Acharya Nagarjuna at Guntur and B. Tech in Electrical \& Electronics Engineering from Jawaharlal Nehru Technological University, Hyderabad. His research interest includes power systems operational and control, FACTS applications in deregulated power systems, and voltage stability. He is a member of IEEE and AMIE (India). 